Winston C.V. Parris MD, John A. Oates MD, Jay Kambam MD, Richard Shmerling MD, John F. Sawyers MD

\title{
Pre-treatment with somatostatin in the anaesthetic manage- ment of a patient with carcinoid syndrome
}

Carcinoid syndrome produces flushing, bronchoconstriction and gastrointestinal hypermotility secondary to serotonin, histamine, bradykinin and prostaglandin release, A variety of drugs, foods and anaesthetic agents may provake this syndrome. Under anaesthesia, the flushing produced may be associated with acute hypotension and cortiovascular collapse; this phenamenon is called a carcinoid crisis. Recently, somarostatin analogue has been used successfully to treat intraoperative carcinoid crisis. In this report, we present a 66-year-old lady with carcinoid syndrome who was pre-ireated with $50 \mu \mathrm{g}$ somatostatin analogue $I V$ and $I M$ prior to surgical manipulation. The anaesthetic course was relatively uneventful and the patient did well postoperatively.

Carcinoid syndrome ${ }^{1}$ is characterized by intermittent flushing of the upper body and face, bronchoconstriction, gastrointestinal hypermotility with diarthoea, telangiectasia and right-sided heart disease. This syndrome results from the secretion of a number of vasoactive substances in patients with carcinoid tumours. ${ }^{2}$ These patients have consistently high levels of the serotonin metabolite, 5-hydroxyindoleacetic acid (5-HIAA), suggesting that the humoral manifestations of carcinoid syndrome may be attributed to the overproduction of serotonin by these tumours. However, other vasoactive substances ${ }^{3}$ may play

\section{Key words}

SYNDROMES: carcinoid syndrome; PHARMACOLOGY: somatostatin.

From the Departments of Anesthesiology, Medicine (J.A.O.) and Surgery (J.F.S.), Vanderbilt University Medical Center, Nashville, Tennessee.

Address correspondence to: Dr. W.C.V. Parris, Department of Anesthesiology, Vanderbilt University Medical Center, Nashville, Tennessee 37232. varying roles in the pathogenesis of this disease, including bradykinin, prostaglandins, histamine, substance $P$ and others of lesser importance.

A variety of drugs, foods, emotions, environmental factors and anaesthetic agents may provoke an acute episode of flusining in patients with carcinoid syndrome. Under anaesthesia, this flushing may be associated with acute hypotension and cardiovascular collapse: ${ }^{4}$ This phenomenon is called carcinoid crisis. Recently, somatostatin $^{5}$ and its synthetic analogue have been used successfully to treat carcinoid crisis intraoperatively. The mechanism of action appears to be the inhibition of mediator release from the tumour. In all previously described cases, somatostatin analogue was used after the development of carcinoid crisis. ${ }^{4}$ We present a patient with carcinoid syndrome who was pre-treated with somatostatin analogue prior to the operative manipulation of the tumour. Apart from transient mild hypotension, the anaesthetic course was relatively uneventful and the patient did well postoperatively.

\section{Case report}

A 66-year-old woman was admitted for elective resection of hepatic metastases of carcinoid tumour. She was diagnosed as having carcinoid syndrome 14 years previously and was treated with 5-fluorouracil intravenously and orally. Her symptoms were well controlled by 5-fluorouracil but this was discontinued eight years later when she developed abnormal liver function tests and thrombocytopaenia. Notwithstanding, she remained reasonably healthy and functioned as a productive schoolteacher and housewife. Her 5-HIAA urinary levels throughout the 14 years of treatment were moderately elevated and ranged from 19 to $45 \mathrm{mg} / 24$ hours (normal < $10 \mathrm{mg} / 24$ hours). During the summer before her current admission, she developed severe flushing of the face and upper body, severe diarthoea and occasional hypertension while her 5-HIAA urinary levels were significantly elevated (120 mg/24 hours) from previous levels.

Further investigation at the time of admission showed 
three discreet nodular metastases of the liver on CT Scan and this was confirmed by magnetic resonance imaging (MRI). Echocardiogram showed tricuspid valve stenosis and tricuspid regurgitation. There was no evidence of right-or left-sided heart failure. Because of her worsening clinical signs and symptoms and the sudden elevation of her urinary 5-HIAA levels, exploratory laparotomy with hepatic resection of metastases was planned.

The patient was classified as ASA physical status III and was premedicated with diazepam $5 \mathrm{mg} P O 90$ minutes prior to surgery. Following the application of the routine monitors (Dinamap BP apparatus, ECG monitor, peripheral nerve stimulator, pulse oximeter, pre-cordial stethoscope and systern for analysis of respiratory and anaesthetic gases), an arterial line and an internal jugular venous line were established. The preoperative blood pressure was $136 / 70 \mathrm{mmHg}$; pulse $74 \cdot \mathrm{min}^{-1}$; mean central venous pressure $15 \mathrm{mmHg}$; electrocardiogram showed normal sinus thythm; oxygen saturation $98 \mathrm{per}$ cent (pulse oximetry). Immediate preoperative laboratory data were: haematocrit, 33,7 per cent, haemoglobin, $11.7 \mathrm{~g}$, platelet count $210,000 / \mathrm{cm}^{3}$, prothrombin time, 12 seconds (control, 12 seconds); partial thromboplastin time, 28 seconds (control, 28 seconds); urinary 5-HIAA, $136 \mathrm{mg} / 24$ hours; sodium, $145 \mathrm{mEq} \cdot \mathrm{L}^{-1}$; potassium, 4.2 $\mathrm{mEq} \cdot \mathrm{L}^{-1}$; chloride, $108 \mathrm{mEq} \cdot \mathrm{L}^{-1} ; \mathrm{CO}_{2}, 26 \mathrm{mmol} \cdot \mathrm{L}^{-1}$; glucose, $90 \mathrm{mg} \cdot \mathrm{dl}^{-1}$; blood urea nitrogen, $20 \mathrm{mg} \cdot \mathrm{dl}^{-1}$.

After pre-oxygenation, anaesthesia was induced with fentanyl $450 \mu \mathrm{g}$ and diazepam $5 \mathrm{mg}$ IV. Tracheal intubation was facilitated by the administration of $8 \mathrm{mg}$ vecuronium IV and a peripheral nerve stimulator was used to determine the optimal intubating conditions. Anaesthesia was maintained with fentanyl (total $1250 \mu \mathrm{g}$ ) nitrous oxide $(2.0 \mathrm{~L})$ and oxygen $(1.0 \mathrm{~L})$ with intermittent isoflurane $(0.25$ to 0.5 per cent).

The patient tolerated induction of anaesthesia without any haemodynamic changes. Skin preparation and draping (performed without significant mechanical stimulation) were uneventful and immediately after incision of the peritoneum but before surgical manipulation commenced, the patient was given somatostatin analogue $50 \mu \mathrm{g} \mathrm{IV}$ and $50 \mu \mathrm{g} \mathrm{SC}$. The somatostatin analogue, considered an experimental drug, was provided by Sandoz Laboratories and Institutional Review Board permission was sought and obtained prior to using the drug. Informed consent was obtained from the patient preoperatively. During the manipulation of the liver the patient developed mild flushing of the head and neck with tachycardia (from a baseline of 60 to $110 \cdot \mathrm{min}^{-1}$ ) and mild bypotension (from baseline $140 / 80$ to $93 / 52 \mathrm{mmHg}$ ). While prcparations to administer more somatostatin were being made, the blood pressure slowly began to rise again and remained in the normal range for the remainder of the operation. Thus, no additional somatostatin was administered.

Laparotomy revealed that the liver was very fibrotic, nodular and cirnotic and that no resectable masses were seen nor palpated. A large carcinoid tumour of the proximal ileum was resected and end-to-end ileal anastomosis was performed. Left oophorectomy was also performed because the left ovary was cnlarged and cystic on gross examination. Subsequent histological examination of both the ileum and the ovary confirmed the diagnosis of carcinoid tumour.

Intraoperative aterial blood gases were within normal limits; central venous pressure did not change significantly during the case and the anaesthetic course was uneventful apart from the previously mentioned brief and mild hypotension. The fentanyl was reversed with naloxone $0.4 \mathrm{mg} \mathrm{IV}$ and naloxone $0.4 \mathrm{mg}$ IM while the vecuronium was reversed with glycopyrtolate $0.8 \mathrm{mg}$ and edrophonium $70 \mathrm{mg}$ IV. The patient was extubated in the operating room and taken to the recovery room in satisfactory condition. She was observed ovemight in the Surgical Intensive Care Unit and was transferred to her room the following day. Her postoperative course was uneventful and she was discharged home on the 12 th postoperative day without any anaesthetic or surgical complications.

\section{Discussion}

The term carcinoid was first used by Oberndorfer ${ }^{6}$ in 1907 to describe the tumours which produce the symptom complex of flushing, bronchoconstriction, diarrhoea and cardiac disease. The term was applied to these tumours because they resembled carcinoma histologically but followed a more benign course than other malignant tumours. Although serotonin ${ }^{7,8}$ appears to be the most important mediator of this syndrome, other mediators do play a major role and they include bradykinin, ${ }^{9}$ histamine, ${ }^{10}$ prostaglandins, ${ }^{11}$ substance $\mathrm{P}^{12}$ and several others. ${ }^{13}$

There are several agents that may evoke flushing in patients with carcinoid syndrome. These include epinephrine, norepinephrine, isoproterenol and dopamine. ${ }^{14}$ It is interesting to note that while the alpha-antagonist phentolamine may prevent flushing induced by epinephrine, norepinephrine and dopamine, propranolol does not block flushing induced by epinephrine. The ingestion of foods may precipitate flushing probably by the consequent release of gastrointestinal hormones which may in turn evoke the release of vasoactive mediators from carcinoid tumours. Some of the gastrointestinal hormones, which have been shown experimentally to produce flushing in susceptible patients, include gastrin, pentagastrin and cholecystokinin. ${ }^{15}$

Somatostatin, ${ }^{16}$ or growth bormone release inhibitory 
homone, has been demonstrated to inhibit the release and the activity of several gastrointestinal hormones and also to inhibit the release of vasoactive mediators from the carcinoid tumour including serotonin. Clinically, it has been used to reverse the flushing, bronchoconstriction and diarrheea associated with carcinoid syndrome. Further, it has been very effective in correcting the hypotension associated with carcinoid crisis intraoperatively and perioperatively. Using this basic information, somatostatin analogue was administered ( $50 \mu \mathrm{g} \mathrm{IV}$ and $50 \mu \mathrm{g} \mathrm{SC}$ ) prior to celiotomy and manipulation of the tumour. During the manipulation of the liver, jejunum and ileum, there was mild hypotension, associated with flushing and tachycardia. While it cannot be proven, we speculate that severe hypotension and carcinoid crisis might have been averted by pre-treatment with somatostatin. The therapeutic effects of somatostatin are limited because of its very short half-life which is two to three minutes. Several analogues have been prepared to overcome this disadyantage. These analogues have greater potency than the tetradecapeptide somatostatin but their duration of action is not significantly extended, ${ }^{17}$ Some somatostatin analogues have also shown selective inhibition of the secretion of one hormone with lesser effects on others. The short duration of somatostatin analgoue also precludes its use as a regular pre-medicant. Instead, it is effective when administered IV to treat a patient with carcinoid crisis after the syndrome is already manifest. Alternatively, somatostatin may be administered prophylactically SC or IM either before induction of anaesthesia or before tumour maripulation. To delay biodegradation and to prolong duration of activity, somatostatin analogue ought to be administered subcutaneously.

General management principles for the patient with carcinoid syndrome include adequate preoperative hydration and the administration of the anti-histaminic agents (diphenhydramine $50 \mathrm{mg}$ ) and anti-serotonin agents ${ }^{18}$ (cyproheptadine and ketanserin) just before or during the induction of anaesthesia. However, it appears that somatostatin has made the use of these agents superfluous. Consequently, these measures were not used in this case More clinical data is required before a firm recommendation can be made at the present time. The operative site should be prepared and draped gently to minimize mechanical stimulation and consequent hypersecretion of sensitive carcinoid tumours. Other specific measures used in this case to avert the onset of carcinoid crisis intraoperatively include the avoidance of thiopentone and the non-depolarizing muscle relaxants with histaminereleasing properties, e.g., atracurium and dtubocurarine. ${ }^{4.19}$ The adrenergic agonists epinephrine, norepinephrine and dopamine are also contraindicated. Succinylcholine is best avoided since the fasciculations produced may increase intra-abdominal pressure with resultant secretion of the vasoactive substances from the turnour.

During carcinoid crises, major fluid shifts may occur in the various body water compartments. Effective treatment is best rendered by haemodynamic monitoring of the patient perioperatively. Central venous pressure monitoring and pulmonary artery cathererization with cardiac output monitoring are desirable especially in patients with cardiac manifestations of carcinoid syndrome. Urinary output measurements, intra-arterial monitoring and frequent blood gas determinations are mandatory.

The major objectives in treating patients with carcinoid syndrome and carcinoid tumours are the reduction of the tumour mass ${ }^{20}$ and control of the disabling symptoms. The first objective may be accomplished by surgical excision when possible. When metastases have occurred, complete excision may not be possible and debulking whenever practical may provide satisfactory palliation. This is particularly true of liver metastases. In our patient, the liver metastases demonstrated on CT scan and magnetic resonance imaging were not palpable on surgical manipulation and consequently, hepatic resection was not done.

Prior to surgery, the disabling symptoms associated with carcinoid syndrome are controlled by a variety of chemotherapeutic agents ${ }^{21}$ with varying degrees of success. Streptozocin and 5-fluorouracil are the agents most commonly used. Our patient was well controlled for eight years with 5-fluorouracil which was discontinued when she developed serious liver dysfunction. Like 5fluorouracil, most of the chemotherapeutic agents are associated with substantial systemic toxicity.

In conclusion, we present a patient with carcinoid tumour associated with carcinoid syndrome scheduled for exploratory laparotomy and hepatic resection. Pretreatment with somatostatin analogue appeared to have prevented the development of carcinoid crisis in this patient. More studies are needed to determine the prophylactic value of somatostatin in the intraoperative management of patients with carcinoid syndrome.

\section{References}

1 Robertson $I S$, Peart WS, Andrews TM. The mechanism of facial flushes in the carcinoid syndrome. $Q \mathrm{~J}$ Med 1962; 31: 103-23.

2 Williams $E D$, Sandler $M$. The classification of carcinoid tumours. Lancet $1963 ; 1:$ :238-9.

3 Levine RJ, Sjoerdsma A. Pressor amines and the carcinojd flush. Ann Intern Med 1963; 58: 818-28.

4. Marsh MH, Martin JK, Kvols LK et al. Carcinoid crisis during anesthesia: successful treatment with a somatostatin analogue. Ancsthesiology 1987; 66: 89-91. 
5 Thulin L, Samnegard $H$, Tyden $G$ et al. Efficacy of somatostatin in a patient with carcinoid syndrome. Lancet 1978; $2: 43$.

6 Oberndorfer $S$. Uber die "kleinen Dumdam-Carcinome." Verh Dtsch Pathol Gest 1907, 11: 113-6

7 Gardner $B$, Dollinger $M$, Silen $W$. Studies of the carcincid syndrome: its relationship to serotonin, bradykinin, and histamine. Surgery 1967; 61: 846-52

8 Lembeck $F, 5$-Hydroxytryptamine in a carcinoid tumor. Nature 1953; 172: 910-1.

9 Oates JA, Pettinger WA, Doctor RB. Evidence for the release of bradykinin in carcinoid syndrome. J Clin Invest $1966 ; 45$ : $173-8$.

10 Roberts $L J$ II, Bloomgarden ZT, Marney SR Jr et al. Histamine release from a gastric carcinoid: provocation by pentagastrin and inhibition by somatostatin. Gastroenterology 1983; 84: 272-5.

11 Patel YC, Rao K. Reichlin 5. Somatostatin in human cerebro-spinal fluid. N Eng J Med 1977; 296: 529-33.

12 Alumets J, Hakanson R. Ingemansson $S$ et al. Substance $P$ and 5-HT in granules isolated from an intestinal carcinoid. Histochemistry 1977; 52: 217-2.

13 Yang $K$, Ulich $T$, Chertg $L$ et al. The neuroendocrine produets of intestinal carcinoids. Cancer 1983; 51: 1918-25.

14 Adamson AR, Peart WS, Grahame-Smith DG et al. Pharmacological blockade of carcinoid flushing provoked by catecholamines and alcohol. Lancet 1969;2: 293-6.

15 Frolich $J C$, Bloomgarden ZT, Oates JA er al. The carcinoid flush. Provocation by pentagastrin and inhibition by somatostatin. N Engl I Med 1978; 299; 1055-7.

16 Dharmsathaphorne $K$, Sherwin RS, Cataland S et al Somatostatin inhibits diarrhea in the carcinoid syndrome. Ann Intern Med 1980; 92: 68-9.

17 Schally AU. Meyer CA. Somatostatin, basic and clinical studies. Mater Med Pol 1982; 12: 28.

18 Mason RA, Steane PA. Carcinoid syndrome: is relevance to the anaesthetist. Anaesthesia 1976; 31: 228-42.

19 Miller R, Patel AU, Warner RRP et al. Anaesthesia for the carcinoid syndrume: a report of nine cases. Can Anaesth Soc J 1978; 25: 240-4.

20 Martin JK, Moertel CG, Adson MA et al. Surgical treatment of functioning metastatic carcinoid tumors. Arch Surg 1983; 118: 537-42.

21 Moertel CG, Hanley JA. Combination chemotherapy trials in metastatic carcinoid tumor and the malignant carcinoid syndrome. Cancer Clin Trials 1979; 2: 327-34.

\section{Résumé}

Le syndrome carcinoide produit du "flushing," bronchoconstriction et hipermotilité gastro-intestinale secandaire $\grave{a}$ la libération de sérotonine, histamine, bradykinine et de prostaglandine. Une variété de médicaments, produits alimentaires et agents anesthésiques peut provoquer ce syndrome. Sous anesthésie, le "flushing" peut être associé à une hypotension aiguëet un collapsus cardiovasculaire; ce phénomène est connu comme étant la crise carcinoïde. Récemment un analogue de la somastotatine a êté utilisé avec succès pour traiter cette crise carcinoide en période peropératoire. On présente ici le cas $d$ ' une femme de 66 ans atteinte d' un syndrome carcinoilde et qui fut pré-traitée avec $50 \mathrm{mg} d^{\prime}$ un analogue à la somastotatine par voie intraveineuse et intramusculaire avant la manipulation chirurgicale. La conduite anesthésique et les suifes postopératoires fureni sans complication. 